Portland State University

PDXScholar

Environmental Science and Management

Faculty Publications and Presentations

$12-2002$

\title{
Pre-logging Liana Cutting Reduces Liana Regeneration in Logging Gaps in the Eastern Brazilian Amazon
}

Jeffrey J. Gerwing

Pennsylvania State University - Main Campus

Christopher Uhl

Pennsylvania State University - Main Campus

Follow this and additional works at: https://pdxscholar.library.pdx.edu/esm_fac

Part of the Forest Biology Commons, and the Forest Management Commons

Let us know how access to this document benefits you.

\section{Citation Details}

Jeffrey J. Gerwing and Christopher Uhl (2002), "Pre-logging Liana Cutting Reduces Liana Regeneration in Logging Gaps in the Eastern Brazilian Amazon." Ecological Applications, 12(6):1642-1651.

This Article is brought to you for free and open access. It has been accepted for inclusion in Environmental Science and Management Faculty Publications and Presentations by an authorized administrator of PDXScholar. Please contact us if we can make this document more accessible: pdxscholar@pdx.edu. 


\title{
PRE-LOGGING LIANA CUTTING REDUCES LIANA REGENERATION IN LOGGING GAPS IN THE EASTERN BRAZILIAN AMAZON
}

\author{
JEFFrey J. Gerwing ${ }^{1,2,4}$ AND Christopher UhL ${ }^{1,3}$ \\ ${ }^{1}$ Interdepartmental Program in Ecology, Pennsylvania State University, University Park, Pennsylvania 16802 USA \\ ${ }^{2}$ Instituto do Homem e Meio Ambiente da Amazônia (IMAZON) Caixa Postal 1015, Belém, Pará, 66.017-000 Brazil \\ ${ }^{3}$ Department of Biology, Pennsylvania State University, University Park, Pennsylvania 16802 USA
}

\begin{abstract}
The cutting of all lianas prior to logging is a reduced-impact logging technique that is predicted to reduce liana proliferation in logging gaps. This study compares liana abundance and species composition in gaps created during conventional and reducedimpact logging in a forest of the eastern Brazilian Amazon. Logging treatments were conducted in side-by-side plots. Shortly following logging, $50-\mathrm{m}^{2}$ plots were located in the approximate centers of four single treefall and four multiple treefall gaps in each logging area. Six years following logging, there were $\sim 40 \%$ fewer climbing lianas in reducedimpact gaps than in conventional logging gaps. In both logging areas multiple-tree gaps had higher liana densities and a higher proportion of lianas recruiting from seed than single tree gaps, where sprouts from cut or fallen lianas were more common. The mean number of liana species encountered per plot did not differ among treatments nor was there any significant difference in species diversity (Fisher's $\alpha$ ) between logging treatments. The results of this study suggest that pre-logging liana cutting can significantly reduce postlogging liana proliferation in gaps, with no discernible negative impact on the species diversity of regenerating lianas.
\end{abstract}

Key words: Amazon, Brazilian; Brazil; forest management, natural; forest, tropical; gap, forest; liana; logging gap; regeneration, forest.

\section{INTRODUCTION}

The management of tropical forests for timber production is often complicated by the presence of lianas. For example, in a forest in the eastern Brazilian Amazon lianas were found to connect each tree of harvestable size to an average of three to nine other large trees (Vidal et al. 1997). Thus, for each tree felled during logging several neighboring trees that would not have otherwise been impacted by the treefall were pulled down or broken off. In addition, lianas may proliferate following logging (e.g., Dawkins 1961, Appanah and Putz 1984, Neil 1984). Abundant lianas in gaps retard tree growth (Putz 1984a) and, in some cases, dense lianas have been found to stall gap succession in a low-stature state by blocking the growth of trees that would establish a high canopy (Schnitzer et al. 2000). Pre-logging liana cutting has been found to mitigate some of these negative effects. For example, liana cutting has been found to reduce felling damage to the residual stand by $\sim 50 \%$ (Fox 1968, Appanah and Putz 1984, but see Parren and Bongers [2001] for a contrasting example). Yet we know little about its impacts on post-logging liana proliferation. With this study we sought to assess the impacts of pre-logging liana cut-

Manuscript received 23 July 2001; revised 11 February 2002; accepted 14 February 2002.

${ }^{4}$ Present address: University Studies, Portland State University, P.O. Box 751, Portland, Oregon 97207 USA.

E-mail: jgerwing@pdx.edu ting on gap-phase regeneration of lianas in a logged forest of the eastern Brazilian Amazon.

Because of their abundance in treefall gaps and other disturbed areas such as abandoned pastures (Putz 1984a, Uhl et al. 1988a), and their rapid growth rates in high light conditions (Baars and Kelly 1996), lianas are generally thought to be light demanding. Because light availability increases with increasing gap size, one might expect a positive relationship between gap size and liana density (e.g., Babweteera et al. 2000). In a logged forest, the larger gaps, formed by the removal of several trees from the same area, might be those predicted to have the most vigorous liana proliferation.

In addition to gap size, post-logging liana proliferation will be influenced by the level of liana recruitment shortly following gap formation. Climbing lianas recruit from a variety of sources. Prior to climbing, many, but not all, species are present as free-standing stems in the forest understory where they commonly make up $\sim 25 \%$ of the upright woody plants $<2 \mathrm{~m}$ tall (Putz 1983, 1984a, Gerwing and Farias 2000). In addition to advanced regeneration, lianas recruit into gaps via seed, sprouts from severed stumps or roots, and sprouts from sections of fallen stems that have produced adventitious roots along their lengths (i.e., layering) (Hegarty 1989). It is the latter of these that is the likely source of many of the liana tangles found in gaps in logged forests. Because many species of lianas have anatomical adaptations that allow them to suffer stem bending and twisting without breaking, they are often able to sur- 
vive serious disturbance (Fisher and Ewers 1991). For example, one study found only $10 \%$ mortality among liana stems whose host trees had fallen (Putz 1984a). Many of these fallen stems are capable of rooting and producing shoots that account for a large proportion of the climbing lianas found in logging gaps (Appanah and Putz 1984).

Pre-logging liana cutting is part of a suite of reducedimpact logging (RIL) techniques designed to minimize logging damage to the residual forest stand. In addition to liana cutting, some of the components of RIL are forest inventorying and mapping, directional felling, and careful log extraction (Barreto et al. 1998). There are two principal reasons to predict that RIL would result in less liana proliferation than conventional logging. First, liana cutting should reduce the number of liana propagules (both liana seeds and fallen liana stems with the potential to layer and sprout) arriving in newly formed gaps. Second, average gap sizes are significantly lower following RIL than conventional logging, in part because RIL results in fewer large gaps created by the felling multiple trees together (Johns et al. 1996).

Here, we test the prediction of reduced liana proliferation following RIL by comparing liana abundance and species composition in single and multiple treefall gaps created during conventional and reduced-impact logging in a forest of the eastern Brazilian Amazon. We also compare liana density in gaps to that of adjacent undisturbed forest, predicting that lianas will be significantly more common in gaps. Finally, we test for a positive relationship between liana abundance and gap size in each of the logging areas.

\section{STUdy Site}

This study was established in a 210-ha patch of oldgrowth forest that showed no visible evidence of prior logging or fire. The site was located $30 \mathrm{~km}$ southeast of the town of Paragominas, Pará, Brazil $\left(3^{\circ} \mathrm{S}, 50^{\circ} \mathrm{W}\right)$. The forests of the region are evergreen and receive $1700 \mathrm{~mm}$ of rainfall annually, occurring mainly from December through May; during the remainder of the year mean monthly rainfall is $\sim 40 \mathrm{~mm}$. Forest stands at the study site are a mosaic of patches that differ in stature, biomass, and liana abundance (Gerwing and Farias 2000). High stature forest patches contain trees 25-40 $\mathrm{m}$ tall and infrequent lianas. Medium stature forest canopy height ranges from 15 to $25 \mathrm{~m}$ and the density of climbing lianas is $\sim 2500$ stems/ha. In low stature patches canopy height is $2-15 \mathrm{~m}$ and liana density is $\sim 5500$ stems/ha. Prior to logging, a 130-ha tract of intact forest at the study site consisted of $18 \%$ high stature, $46 \%$ medium stature, $28 \%$ low stature forest, and $8 \%$ natural treefall gaps, in which canopy height was $<2 \mathrm{~m}$, resulting in a mean total aboveground live biomass of $314 \mathrm{Mg} / \mathrm{ha}$ (Gerwing and Farias 2000). The soils of the region are clay-rich, oxisols and ultisols.

\section{Methods \\ Logging treatments}

The logging treatments included unplanned conventional logging, the industry standard for the region, and RIL in adjacent plots of 80 and 105 ha, respectively. All climbing lianas were cut in the RIL area during March 1991 and the entire study site was logged during October and November 1993. Conventional logging resulted in $20-40 \%$ reductions in forest canopy cover and density of trees $>10 \mathrm{~cm}$ diameter (Johns et al. 1996). In addition, for every tree extracted, nearly 500 $\mathrm{m}^{2}$ of the forest floor was disturbed and 51 trees $>10$ $\mathrm{cm}$ in diameter were damaged. Compared to conventional logging, the use of RIL resulted in $10 \%$ less forest canopy cover loss and a $40 \%$ reduction in the number of trees $>10 \mathrm{~cm} \mathrm{dbh}$ that were damaged or destroyed (Johns et al. 1996). Also, following RIL only $25 \%$ of all gaps contained more than one tree whereas $50 \%$ of the gaps in the conventionally logged area contained two or more trees. This difference in the proportion of gaps containing multiple trees contributed to a nearly $50 \%$ lower mean gap size following RIL than conventional logging (166 $\mathrm{m}^{2}$ for RIL vs. $355 \mathrm{~m}^{2}$ for conventional logging) (Johns et al. 1996).

\section{Liana sampling}

To quantify liana regeneration in logging gaps, we installed $5 \times 10-\mathrm{m}$ plots in the centers of logging gaps in the RIL and conventional logging areas 8 mo following logging. In each logging area four single tree gaps, and four multiple tree gaps were randomly selected from the total population of logging gaps for a total of 16 study gaps. To help ensure that single and multiple treefall gaps represented distinct size classes we included as multiple tree gaps only those formed by the felling of three or more trees. In each plot, all lianas $\geq 5 \mathrm{~cm}$ tall that were rooted in the plot were measured, identified, classified according to their mode of recruitment (i.e., newly recruited seedling, sprout from a layered fallen stem (i.e., a stem that had produced adventitious roots along its length), root/stump sprout, or advanced regeneration), and marked with numbered aluminum tags. The diameter of each climbing stem was measured at $1.3 \mathrm{~m}$ above the ground or below the first branch, whichever came first. Because we were interested in quantifying the abundance of potentially independent liana stems in the plots, each liana with its own root system was counted. Thus individual genets were sometimes sampled more than once. Lianas were identified to species by Nelson Rosa of the Museu Emilio Goeldi, Belém, Pará, Brazil, a field botanist with $20 \mathrm{yr}$ of experience working in the region. The total area of each gap was estimated by measuring the distance from the approximate center of the gap to the canopy edge of the surrounding vegetation along eight compass bearings, joining the end 


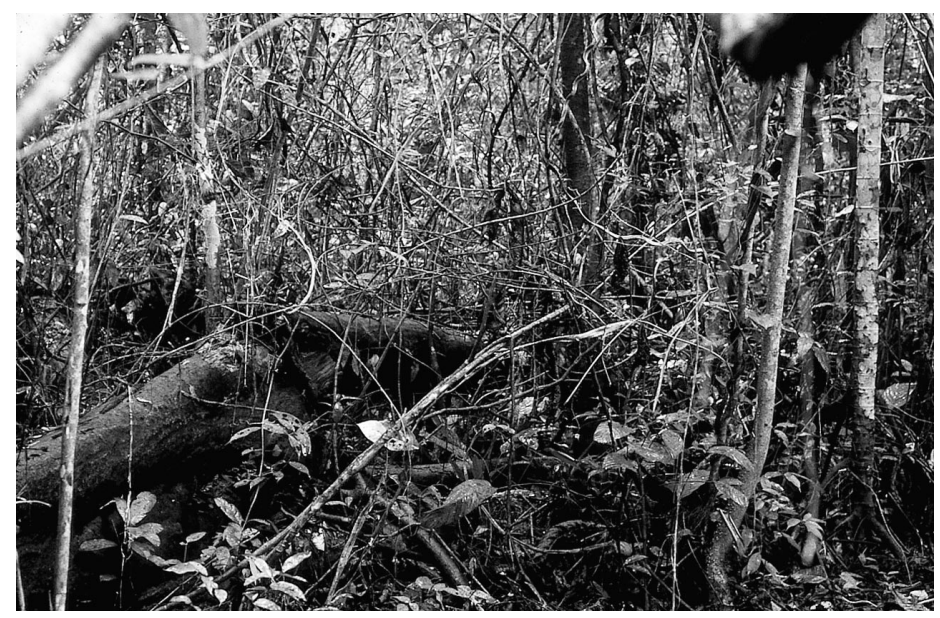

Plate 1. A 6-yr-old single-tree logging gap formed as part of a conventional logging operation near Paragomins, Pará, Brazil. Photograph by J. Gerwing.

points of these radii on a map, and summing the areas of the triangular pieces.

Plots were inventoried again $6 \mathrm{yr}$ after logging (see Plate 1). In some cases minor excavation was required to determine the mode of recruitment for stems that had established between inventories. At this time, we also sampled a plot under undisturbed forest canopy that was paired with each of the gap plots. Forest plots were located $10 \mathrm{~m}$ from the edge of the gap in a randomly chosen compass bearing from the approximate gap center with the restriction that potential plot locations that fell within $10 \mathrm{~m}$ of a neighboring gap were rejected and the selection process was repeated.

Several months after the second gap plot inventory, we assessed liana cover in 35 additional randomly selected gaps in each of the logging treatment areas. Both single and multiple tree gaps were included in this sample. The purpose of this expanded sample was to assess the degree of liana infestation of gaps at the stand level and to quantify the relationship between gap size and liana cover in each of the logged areas. To assess liana cover, we first divided each gap into four roughly equal sections by bisecting it with two perpendicular lines that passed through the approximate center of the gap. Within each of the resulting quarters, we randomly selected a compass bearing to establish a sampling transect from the center of the gap to its edge. Along each of these transects, we tallied liana cover at 1-m intervals using a dichotomous rating, considering a point to be liana covered if more half of the leaf area at the canopy surface was lianas and not liana covered if there were leaves of other types of plants or open sky. The liana cover of each gap was calculated as the number of liana-covered sample points divided by the total number of sample points.

\section{Analysis}

Statistical analysis of the effects of gap type (i.e., single vs. multiple treefall) and logging treatment on liana abundance were conducted using the balanced
ANOVA routine of Minitab 11.21 (Minitab 1996). Although logging treatment was unreplicated, the large sizes of the logging areas and the apparent uniformity in pre-logging liana stem densities between them (Vidal et al. 1997) minimized the risk of confounding treatment effects with preexisting differences between areas. Nonetheless, statistical analysis of logging treatment effects should be interpreted with some caution. We assessed differences in liana stem density and basal area between gap and forest sites for each combination of logging treatment and gap type using paired $t$ tests with sequential Bonferroni corrections to control group-wide Type II error rates among the eight individual tests (Holm 1979, Rice 1989).

Liana species diversity in the gap plots $6 \mathrm{yr}$ after logging was quantified using Fisher's $\log$ series $\alpha$, a species diversity index that has low sensitivity to differences in sample size (Magurran 1988). The effects of gap size and logging treatment on species diversity were assessed using ANOVA. To compare species composition among combinations of logging treatment and gap size we used the Morisita-Horn index (here symbolized by $\mathrm{MH}$ ). This is a quantitative similarity index that incorporates both the extent of species overlap between samples and their similarity in relative abundance of co-occurring species (Magurran 1988). To calculate the $\mathrm{MH}$ indices, we first summed the data from each of the four replicate plots for each combination of logging treatment and gap type into a master list for that treatment combination. We then calculated the indices for the six possible pairwise comparisons among the four master lists.

\section{REsUlts}

\section{Liana stem density and mode of recruitment}

Six years following logging, the density of climbing lianas differed significantly between logging treatments (Table 1). RIL gaps had fewer liana stems than their conventionally logged counterparts (Fig. 1) and in both 
TABLE 1. ANOVA for the density of free-standing and climbing lianas in 6-yr-old logging gaps created during conventional and reduced-impact logging near Paragominas, Pará, Brazil.

\begin{tabular}{lrccc}
\hline \hline Source of variation & df & MS & $F$ & $P$ \\
\hline Free-standing stems & & & & \\
$\quad$ Treatment & 1 & 0.154 & 4.28 & 0.061 \\
$\quad$ Gap type & 1 & 0.000 & 0.00 & 0.990 \\
$\quad$ Treatment $\times$ Type & 1 & 0.015 & 0.42 & 0.530 \\
$\quad$ Error & 12 & 0.036 & & \\
Climbing stems & & & & \\
$\quad$ Treatment & 1 & 0.815 & 12.81 & 0.004 \\
$\quad$ Gap type & 1 & 0.363 & 5.71 & 0.034 \\
Treatment $\times$ Type & 1 & 0.014 & 0.22 & 0.650 \\
$\quad$ Error & 12 & 0.064 & & \\
\hline
\end{tabular}

Notes: Treatment compares the two types of logging. Gap type compares single and multiple tree gaps.

logging treatments, multiple tree gaps had more climbing stems than single tree gaps (Table 1, Fig. 1). Freestanding lianas $\geq 10 \mathrm{~cm}$ tall had lower stem densities in RIL gaps than in conventional logging gaps ( $45 \%$ lower for multiple tree gaps and $27 \%$ for single tree gaps) but given the relatively small sample size, these differences were not statistically significant $(P=$ 0.061; Table 1). The density of free-standing lianas was nearly equal between gap types within each of the logging treatments (Fig. 1).

The basal area of climbing liana stems was also significantly lower in RIL gaps than in conventional logging (Table 2). This difference was most pronounced for single tree gaps, where RIL gaps had 58\% less liana basal area of climbing lianas than conventional gaps (Fig. 2). In contrast to the significant effect on liana stem density, gap type (i.e., multiple or single tree) did not significantly affect liana basal area (Table 2). This
TABLE 2. ANOVA for the basal area of climbing lianas in 6-yr-old logging gaps created during conventional and reduced-impact logging near Paragominas, Pará, Brazil.

\begin{tabular}{lrcrc}
\hline \hline Source of variation & df & MS & $F$ & $P$ \\
\hline Treatment & 1 & 0.581 & 15.22 & 0.002 \\
Gap type & 1 & 0.061 & 1.60 & 0.229 \\
Treatment $\times$ Type & 1 & 0.069 & 1.80 & 0.204 \\
Error & 12 & 0.038 & & \\
\hline
\end{tabular}

Notes: Treatment compares the two types of logging. Gap type compares single and multiple tree gaps.

lack of a significant difference was largely do to the nearly equal mean liana basal area between multiple and single tree gaps in the conventional logging area (Fig. 2).

In addition to differing in liana abundance, logging treatments and gap types also differed in the source of the regenerating lianas (Figs. 1 and 2). Liana establishment from seed was common in multiple tree gaps, where seedlings accounted for $52 \%$ of the climbing stem density and $49 \%$ of basal area in the conventional logging area and $34 \%$ and $48 \%$ of density and basal area, respectively, in the RIL area. This contrasts with the low representation of seedlings in single tree gaps; only $9 \%$ of the climbing stems in the RIL area and $14 \%$ of those in the conventional logging originated as seedlings. Vegetative propagation, including root/ stump sprouting and the layering of fallen stems, was most important in single tree gaps in conventional logging where it accounted for $\sim 80 \%$ of climbing stem density and basal area. In all treatment combinations, stems originating as sprouts from layered stems were conspicuously absent among the free-standing stems (Fig. 1). A possible explanation for this was that these sprouts seemed to either attain climbing status over the
FIG. 1. Density of lianas by mode of regeneration in multiple and single tree gaps six years after conventional (left bar of each pair) and reduced-impact (right bar of each pair) logging near Paragominas, Pará, Brazil. Data are means +1 SD. $N=4$ gaps per treatment combination.

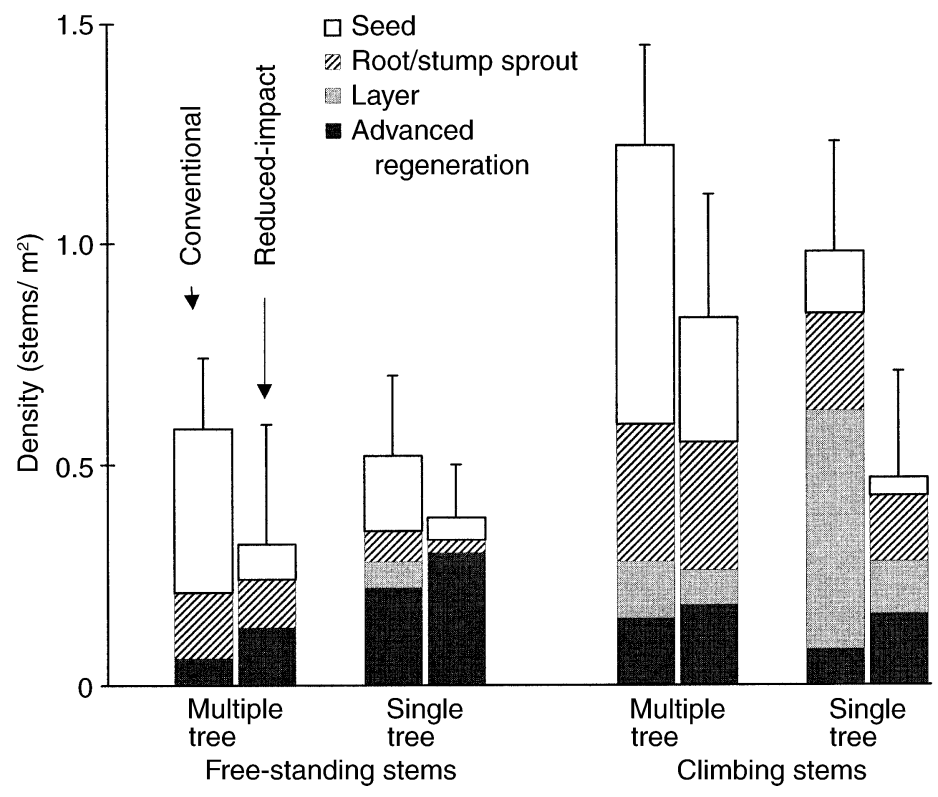




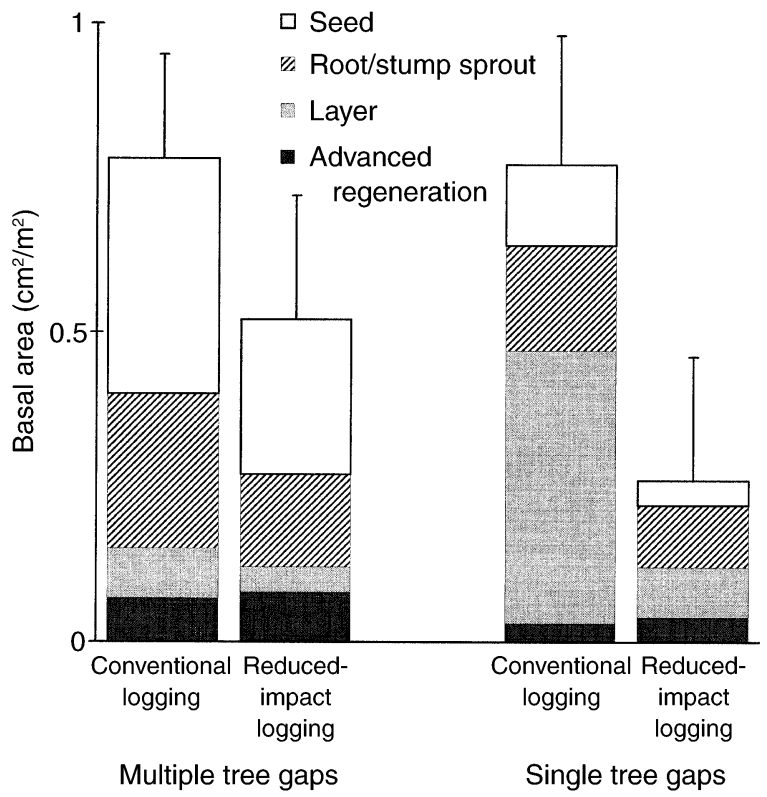

FIG. 2. Basal area of climbing lianas by mode of regeneration in multiple and single tree gaps six years after conventional and reduced-impact logging near Paragominas, Pará, Brazil. Data are means +1 SD. $N=4$ gaps per treatment combination.

course of the study or die; few remained free-standing (J. Gerwing, personal observation). Stems present as advanced regeneration prior to gap formation were present in all combinations of gap type and logging treatment accounting for over half of the free-standing stems in single tree gaps in both logging areas but never accounted $>30 \%$ of the total climbing stem density or $15 \%$ of basal area in any of the treatment combinations.

In both logging areas there were significantly higher densities of climbing lianas in gaps than in adjacent patches of undisturbed forest (Table 3 ). In the conventional logging area there were three to four times as many climbing lianas in gap plots as in adjacent forest plots. Liana basal area in the gaps, however, was approximately half that of undisturbed forest. In the RIL area, where all lianas had been cut prior to logging, mean liana density in gaps was seven to eight times that found in adjacent forest plots. Liana basal area was also significantly higher in multiple tree gaps than in undisturbed forest but there was no difference between forest and single tree gaps.

\section{Liana species diversity}

In total, 75 species of lianas were recorded in the 16 gap plots. Six additional morphospecies, identified only to family or genus, and one unidentified liana were also recorded. Eight species were represented in all of the treatment combinations. In contrast, 19 species were represented by single individuals in the total sample. The ten most common species accounted for $\sim 50$ to $70 \%$ of the total liana stems in each of the combinations of gap type and logging treatment (Table 4). Four species Bauhinia guianensis, Adenocalyma prancei, Memora schomburgkii, and Croton ascendens were among the ten most common in each of the treatment combinations. The first three of these species, in addition to recruiting from seed, were common as free-standing advanced regeneration in the understory of undisturbed patches of forest. However, C. ascendens, and four other species that were common in multiple tree gaps (namely, Gouania pyrifolia, Tournefortia laevigata, Davilla kunthii, and Passiflora glandulosa), recruited exclusively from seed. Three other species (Salacia megistophylla, Combretum laxum, and Arrabidea trailii) were encountered only as shoots from layered fallen stems and were among the most common in the single treefall gaps in the conventional logging area.

Liana species diversity in gaps was not significantly affected by logging treatment (Table 5). The mean number of species encountered per plot varied little among treatments (range 18-21). Increased evenness in spe-

TABLE 3. Comparison of the abundance of climbing lianas in gaps and in plots in adjacent patches of forest that were not directly impacted by logging, six years following conventional and reduced-impact logging near Paragominas, Pará, Brazil (means and 1 SD).

\begin{tabular}{lcccc}
\hline \hline \multicolumn{1}{c}{ Treatment } & Density $\left(\mathrm{stems} / \mathrm{m}^{2}\right)$ & $P$ value & $\begin{array}{c}\text { Basal area } \\
\left(\mathrm{cm}^{2} / \mathrm{m}^{2}\right)\end{array}$ & $P$ value \\
\hline Conventional logging & & & & \\
$\quad$ Single tree gaps & $0.98(0.25)$ & $0.006^{*}$ & $0.78(0.21)$ & 0.025 \\
Adjacent forest & $0.35(0.11)$ & & $1.68(0.77)$ & \\
Multiple tree gaps & $1.22(0.23)$ & $0.001^{*}$ & $0.78(0.17)$ & 0.045 \\
Adjacent forest & $0.31(0.27)$ & & $1.73(0.91)$ & \\
Reduced-impact logging & & & \\
Single tree gaps & $0.47(0.24)$ & $0.010^{*}$ & $0.26(0.20)$ & 0.268 \\
Adjacent forest & $0.07(0.05)$ & & $0.18(0.13)$ & \multirow{2}{*}{$0.009^{*}$} \\
Multiple tree gaps & $0.83(0.28)$ & $0.006^{*}$ & $0.52(0.20)$ & \\
Adjacent forest & $0.10(0.05)$ & & $0.12(0.06)$ & \\
\hline
\end{tabular}

Notes: $P$ values are from paired, one-tailed $t$ tests comparing gap and forest plot means. $N$ $=4$ plots.

$* P<0.05$ after sequential Bonferroni corrections were applied. 
TABLE 4. The number of stems $\geq 10 \mathrm{~cm}$ tall of the ten most common species of lianas encountered in four $50-\mathrm{m}^{2}$ plots in 6-yr-old gaps in forest subjected to conventional and reduced-impact logging (RIL) near Paragominas, Pará, Brazil.

\begin{tabular}{|c|c|c|c|c|c|}
\hline \multirow[b]{2}{*}{ Species } & \multirow{2}{*}{$\begin{array}{l}\text { Observed } \\
\text { regeneration } \\
\text { modes }\end{array}$} & \multicolumn{2}{|c|}{$\begin{array}{l}\text { Conventional } \\
\text { logging }\end{array}$} & \multicolumn{2}{|c|}{ RIL } \\
\hline & & $\begin{array}{c}\text { Single } \\
\text { tree }\end{array}$ & $\begin{array}{c}\text { Multiple } \\
\text { tree }\end{array}$ & $\begin{array}{c}\text { Single } \\
\text { tree }\end{array}$ & $\begin{array}{c}\text { Multiple } \\
\text { tree }\end{array}$ \\
\hline Adenocalyma pranceii A. Gentry & A, $S$ & 19 & 25 & 9 & 22 \\
\hline Bauhinia guianensis Auble & A, $S$ & 27 & 52 & 12 & 41 \\
\hline Bauhinia rutilans Spr. Ex Bth & A, $\mathrm{S}$ & 19 & & 10 & \\
\hline Bauhinia siqueiraeii Ducke & A, S & & 8 & 8 & \\
\hline Bauhinia cupreonitans Ducke & A, S & & & & 7 \\
\hline Memora schomburgkii (DC.) Miers & $\mathrm{S}, \mathrm{A}, \mathrm{C}$ & 8 & 33 & 5 & 25 \\
\hline Croton ascendens R. Secco and N. Rosa & $\mathrm{S}$ & 8 & 9 & 4 & 7 \\
\hline Gouania pyrifolia Reiss & $\mathrm{S}$ & & 10 & 5 & 7 \\
\hline Tournefortia laevigata Lam. & $\mathrm{S}$ & & 11 & & 7 \\
\hline Davilla kunthii ST. Hil. & $\mathrm{S}$ & & 16 & & 11 \\
\hline Passiflora glandulosa Cav. & $\mathrm{S}$ & & 13 & & \\
\hline Memora bracteosa (DC) Bur ex K. Schum & $\mathrm{C}$ & & & 12 & \\
\hline Acacia multipinnata Ducke & $\mathrm{L}, \mathrm{C}, \mathrm{S}$ & 11 & 12 & & \\
\hline Dalbergia subcymosa Ducke & $\mathrm{L}, \mathrm{C}$ & 14 & & 5 & 7 \\
\hline Doliocarpus gracilis Kubitzki & $\mathrm{L}$ & & & 17 & 10 \\
\hline Salacia megistophylla Standl & $\mathrm{L}$ & 13 & & & \\
\hline Combretum laxum Jacq & $\mathrm{L}$ & 12 & & & \\
\hline Arrabidaea trailii Sprague & $\mathrm{L}$ & 9 & & & \\
\hline Total ten most common species & & 140 & 189 & 87 & 144 \\
\hline Total of all species & & 252 & 273 & 170 & 222 \\
\hline
\end{tabular}

Notes: Each species was classified according to its observed modes of regeneration: $\mathrm{S}=$ seed, $\mathrm{C}=$ coppice/root sprout, $\mathrm{L}=$ layer (i.e., sprout from rooted section of fallen stem), and $\mathrm{A}=$ advanced regeneration.

cies representation in the RIL gaps resulted in a trend of higher values for Fisher's $\alpha$ (Table 5) but this difference was not significant (log transformed data; $F=$ $3.80, \mathrm{df}=1,12, P=0.075$ ). Nor was there a significant difference in values for Fisher's $\alpha$ between gap types ( $\log$ transformed data; $F=2.02$, df $=1,12, P=0.181$ ).

Interestingly, the values of the Morisita-Horn index of species similarity, which ranges from 0 (when there are no species in common) to 1 (when all species share in equal relative proportions) were highest for treatment combinations that had gap type in common and not for those in the same logging treatment (Table 6). The two highest index values were for the pairs that

TABLE 5. Liana species diversity characteristics of $50-\mathrm{m}^{2}$ plots $(N=4$ treefall gaps of each size) in the centers of 6 -yr-old gaps formed during conventional and reduced impacts logging near Paragominas, Pará, Brazil (means, with $1 \mathrm{SD}$ in parentheses).

\begin{tabular}{lllr}
\hline \hline & $\begin{array}{c}\text { No. liana } \\
\text { stems } \\
\text { sampled }\end{array}$ & $\begin{array}{c}\text { No. liana } \\
\text { species } \\
\text { recorded } \dagger\end{array}$ & Fisher's $\alpha$ \\
\hline Treatment & & & \\
Conventional logging & & & \\
$\quad \begin{array}{l}\text { Single tree gaps } \\
\text { Multiple tree gaps }\end{array}$ & $82(10)$ & $21(3)$ & $10.7(2.1)$ \\
Reduced-impact logging & & $20(2)$ & $8.7(1.7)$ \\
$\quad \begin{array}{l}\text { Single tree gaps } \\
\text { Multiple tree gaps }\end{array}$ & $39(16)$ & $18(5)$ & $12.3(3.1)$ \\
\hline
\end{tabular}

Note: Multiple tree gaps included three or more trees.

$\dagger$ Includes six morphospecies that were identified to genus or family. included the multiple tree gaps $(\mathrm{MH}=0.91)$ and the single tree gaps $(\mathrm{MH}=0.65)$ in both areas. The values for all other pairs of treatment combinations ranged from $\mathrm{MH}=0.47$ to $\mathrm{MH}=0.57$.

\section{Liana cover and gap size}

In both logging areas, the gap size data were nonnormal and skewed towards smaller gaps. The median area of the 35 gaps sampled in each logging treatment was significantly greater in the conventional logging operation (median gap area $260 \mathrm{~m}^{2}$ ) than in the RIL area (median gap area $160 \mathrm{~m}^{2}$ ) (one-tailed Mann-Whitney test, $W=885.5, P<0.0001)$. The conventional logging gaps also had a mean canopy cover by lianas that was almost twice that of RIL gaps $(53 \pm 25 \%$ vs.

TABLE 6. Morisita-Horn indices of quantitative liana species similarity among 6-yr-old gaps in forest subjected to conventional and reduced-impact (RIL) logging near Paragominas, Pará, Brazil.

\begin{tabular}{lcccc}
\hline \hline & \multicolumn{2}{c}{ RIL } & & \multicolumn{2}{c}{ Conventional logging } \\
\cline { 2 - 2 } \cline { 5 - 5 } Gap type & $\begin{array}{c}\text { Multiple } \\
\text { tree }\end{array}$ & & $\begin{array}{c}\text { Single } \\
\text { tree }\end{array}$ & $\begin{array}{c}\text { Multiple } \\
\text { tree }\end{array}$ \\
\hline RIL & & & \\
$\quad$ Single tree & 0.56 & & 0.65 & 0.47 \\
$\quad$ Multiple tree & & & 0.57 & 0.91 \\
Conventional logging & & & \\
$\quad$ Single tree & & & 0.57 \\
\hline
\end{tabular}

Note: Small gaps were formed by the felling of a single tree and large gaps included three or more trees. 


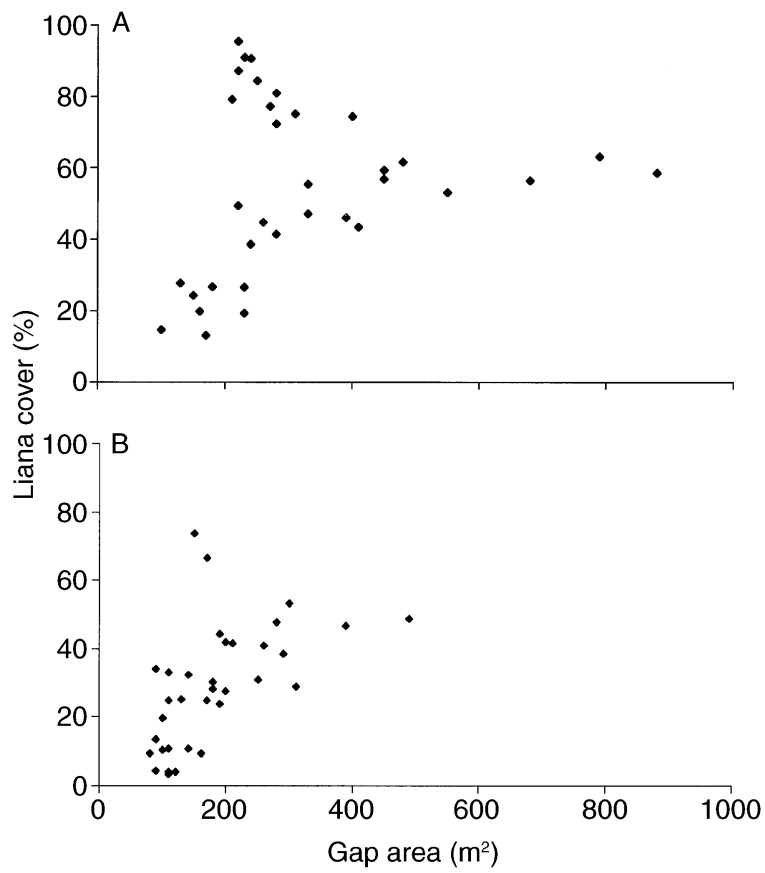

FIG. 3. The relationship between liana cover and gap area in 6-yr-old gaps formed during (A) conventional and (B) reduced-impact logging near Paragominas, Pará, Brazil. $N=$ 35 gaps per logging treatment.

$28 \pm 18 \% ; t=4.81, \mathrm{df}=62, P \leq 0.0001)$. There were 20 (57\% of the total gaps) with $>50 \%$ liana cover in the conventional logging and three $(9 \%$ of the total gaps) in the RIL. In both areas liana cover increased with increasing gap size to maximum values of $60-$ $90 \%$ liana cover in gaps that were 200-300 $\mathrm{m}^{2}$ (Fig. 3 ). However, this positive relationship between liana cover and gap size did not hold for large gaps (i.e., those $>400 \mathrm{~m}^{2}$ ) where liana cover consistently fell between 40 and $60 \%$.

\section{DISCUSSION}

\section{Differences in liana community structure between logging treatments}

As hypothesized, pre-logging liana cutting combined with other reduced-impact logging techniques significantly reduced liana proliferation in 6-yr-old logging gaps in the study forest. In the smaller, single tree gaps, this effect was largely the result of a sharp reduction of layering fallen lianas as a source of regenerating stems. A previous study in Malaysia found that $53 \%$ of the climbing lianas in 6-yr-old logging gaps originated as sprouts of fallen lianas (Appanah and Putz 1984). In the current study such stems accounted for $55 \%$ of the climbing stems in single tree gaps in the conventional area compared to only $9 \%$ in the RIL area. Of this $9 \%$, nearly all of the stems were Dolicarpus gracilis, one of the ten most common species encountered in single tree gaps the in RIL area (Table 4). In the study forest, D. gracilis is a common, thin-stemmed liana (maximum diameter $\sim 3 \mathrm{~cm}$, but commonly much thinner) that was frequently left uncut by liana cutting crews (J. Gerwing, personal observation).

In multiple tree gaps the difference between the two treatments was largely the result of reduced liana seedling establishment following RIL. Total seedling density (including climbing and free-standing stems) in multiple tree gaps following conventional logging was $1 \mathrm{stem} / \mathrm{m}^{2}$ (56\% of the total stem density) compared to $0.3 \mathrm{stem} / \mathrm{m}^{2}$ ( $28 \%$ of the total stem density) in the RIL area. It is difficult to compare these numbers to other studies because previous studies have not distinguished among different regeneration modes of establishing lianas. However, one gap study conducted in the Venezuelan Amazon included a treatment where all advanced regeneration and fallen liana stems were removed at the time of gap formation (Uhl et al. 1988b). Four years following gap formation liana density in these treated plots in a multiple tree gap was 0.9 stems/ $\mathrm{m}^{2}$ compared to $4.1 \mathrm{stems} / \mathrm{m}^{2}$ in untreated control plots. Based on these data, seedlings contributed, at most, $21 \%$ of the total liana stem density in the Uhl et al. study, thus suggesting that seedlings played a substantially smaller role in the regeneration of lianas than they did in the current study.

The establishment of seedlings in the conventional logging area was facilitated by the high level of soil disturbance compared to the RIL area. On average, 43 $\mathrm{m}^{2}$ of ground area were disturbed by machine maneuvering in the bole zone for each tree extracted during conventional logging compared to only $11 \mathrm{~m}^{2}$ during RIL (Johns et al. 1996). A sharp reduction in the density of mature climbing lianas capable of producing seed is likely to have also contributed to the lower level of seedling establishment in the RIL area. Perhaps more surprising than the reduced seedling density was the finding that establishing seedlings were relatively common in RIL gaps. We were unable determine the origins of these seeds, however, there are several possible sources. One likely source was the soil seed bank, where liana seeds are often present, albeit at low densities (Kennedy and Swaine 1992, Dalling and Denslow 1998). In addition, even though an attempt was made to cut all climbing lianas, $\sim 180$ stems/ha, $7 \%$ of the total climbing lianas, were missed by the cutting crews and could have served as seed sources (Gerwing and Vidal 2002).

In spite of its negative effects on liana stem density, pre-logging liana cutting had no discernible negative impacts on liana species diversity in gaps. This result suggests that reductions in stem density came largely at the expense of reduced recruitment of relatively common species and that a diverse liana species assemblage was able to recruit in the near absence of adult stems. The result of a reduction in liana stem density not being paralleled by a reduction in diversity also supports the conclusion of a rarefaction simulation analysis that gaps in a forest in Panama maintained liana species 
diversity via mechanisms that were not merely related to high stem density (Schnitzer and Carson 2001). The authors of that study suggest that high liana species diversity in gaps may result, in part, from the diverse methods of gap colonization that lianas employ. In the current study, four distinct modes of recruitment were observed in both conventional and reduced-impact logging gaps. Also, many of the species that we encountered were capable of recruiting via multiple methods (Table 4), thus increasing their changes of establishing in a given gap.

\section{Changes in liana cover with increasing gap size}

The results of this study provide some support for the hypothesis that liana cover increases with increasing gap size but the observed relationship was not one of simple linear increase. Among small to mediumsized gaps in both logging areas, there was a positive relationship between liana cover and gap size. However, the highest values of liana cover (i.e., $>70 \%$ ) were not found in the largest gaps (i.e., those $>400 \mathrm{~m}^{2}$ ), which had consistently between $40 \%$ to $60 \%$ liana cover.

One explanation for the plateau of liana cover among the largest gaps may be related to the relatively high abundance of trees of pioneer species (e.g., Cecropia sp., Vismia sp., and Trema micrantha) in these gaps (J. Gerwing, personal observation). Where pioneer trees are abundant liana growth may be suppressed by rapidly developed tree canopy cover and because these species are ill-suited as liana hosts owing to their large leaves, flexible stems, rapid growth, and in the case of Cecropia, monopodial growth form (Putz 1984b). A study in Suriname found that the contribution of liana leaves to total leaf biomass dropped from a forest-wide average of $\sim 7 \%$ to only $3 \%$ in patches dominated by Cecropia sp. (Beekman 1981).

Another explanation for the lack of further increase in liana cover among the largest gaps may lie in the differences in the sources of regenerating lianas among different sizes of gaps and the relatively short time that had passed since gaps formation. Of the 16 gaps that were closely studied, the multiple tree gaps had the highest proportions of lianas establishing from seed and these stems were, on average, smaller diameter than the sprouts from stumps and fallen liana stems that were more common in the smaller gaps. Indeed although mean liana stem density was significantly higher in the multiple tree gaps than in smaller single tree gaps, there was no significant difference in mean liana basal area between gap types (Table 2). Because of the log-log relationship between liana stem basal area and total leaf area (Gerwing and Farias 2000), a given total basal area in a few thick-stemmed lianas will support more leaf area than an equal amount of basal spread among many thin stems. Thus, small to medium-sized gaps with relatively few large diameter lianas originating as coppice sprouts could have had larger portions of their canopy surfaces dominated by lianas than larger gaps were many of the lianas were thin-stemmed having originated as seedlings. Ultimately, if most of the newly recruited lianas survive and grow to larger diameters, the forests regenerating from large gaps, because of their higher liana stem densities, are likely to have higher overall liana abundance, in terms of biomass and leaf area, than smaller gaps.

\section{Implications for the management of Amazonian forests}

One limitation of this study is that our results are based on a single assessment conducted $6 \mathrm{yr}$ postlogging in a system where cutting cycles in managed forests are likely to be on the order of 30-40 yr (Barreto et al. 1998). However, there are several lines of evidence to suggest that differences we have documented among gap types and logging treatments will be persistent. First, the majority of recruitment into gaps is likely to occur during the first 2 yr following gap establishment (Uhl et al. 1988). Thus, most of the plants that will make up the future vegetation in the study gaps were likely to have already established by the time we conducted our 6-yr inventory. Second, a study of natural forest gaps in Panama found nearly identical liana species diversity and density when 5- and 10-yrold gaps were compared (Schnitzer and Carson 2001). This suggests that in the medium term, at least, liana density and species diversity may remain relatively constant. Finally, abundant lianas, once established, may persist in gaps for many $(>13)$ years beyond the time when the canopies of most gaps have closed (Schnitzer et al. 2000). Thus, elevated liana abundance in gaps compared to forest understory is likely to represent a relatively long-term change to forest structure.

The results of this study suggest that with respect to liana regeneration, 6-yr-old logging gaps at the study site could be grouped into three broad classes. The first class included large gaps $\left(>400 \mathrm{~m}^{2}\right)$, where newly recruited seedlings and sprouts from roots and stumps, were the major source of regenerating lianas. Liana cover ranged from $40 \%$ to $60 \%$ and liana proliferation was likely limited by competition from pioneer trees. This situation contrasts with a study of logging gaps in a forest in Uganda where liana cover increased steadily with gap size to a consistent $100 \%$ in the largest gaps (Babweteera et al. 2000). Part of the explanation for the higher levels of liana proliferation in large gaps in the Ugandan study, compared to the forest we studied, might be that the guild of aggressive, fastgrowing, large-leafed pioneer tree species that is commonly found in neotropical forests was largely absent from the Ugandan forest (Chapman et al. 1999). The second class of logging gaps were mostly medium sized $\left(200-400 \mathrm{~m}^{2}\right)$ and are distinguished by having liana cover $\geq 60 \%$ where sprouts from lianas that fell in the canopies of felled trees was the principal source of regenerating lianas. The third class of logging gaps consisted of small to medium-sized gaps (100-400 $\left.\mathrm{m}^{2}\right)$ 
where sprouts, advanced regeneration, and seedlings each contributed to the pool of regenerating lianas. In these gaps liana cover ranged from $<10 \%$ to $50 \%$ and within this class, there was an apparent positive relationship between liana cover and gap size.

One of the primary differences between the two logging treatments with respect to liana regeneration was the difference in the relative proportion of the three classes of gaps. For example, among the 35 gaps sampled in the conventional logging area, $11(31 \%)$ were of the first class (i.e., large gaps dominated by pioneer trees) whereas there were only two $(6 \%)$ such gaps in the sample from the reduced-impact logging area. In addition, $11(31 \%)$ of the gaps sampled in the conventional logging area and only two $(6 \%)$ of the those in the reduced impact area belonged to the second class (i.e., medium sized and dominated by lianas). From a silvicultural perspective, this is an important difference because high levels of liana cover are likely to impede the regeneration and growth of timber species in logging gaps (Fox 1976, Buschbacher 1990, Fredericksen and Mostacedo 2000). Furthermore, it is likely that many liana-dominated gaps will remain in a low stature condition for several decades (Schnitzer et al. 2000), making them unproductive for the foreseeable future.

When considering how the results of this study might be extrapolated to other regions, it is important to note that liana stem density and aboveground liana biomass at the study site are relatively high (Gerwing and Farias 2000) compared to other sites that have been studied in the Amazon basin (e.g., Klinge and Rodriguez 1973, Laurence et al. 2001). Given the importance of prelogging liana abundance in determining post-logging liana proliferation, in forests where liana density is lower, the proportion of liana-dominated gaps that develop following logging is likely to be less than what we have reported here. Nevertheless, give the patchy nature of liana occurrence within many tropical forests (Hegarty and Caballé 1991), some liana-dominated gaps are likely to result even in regions where mean liana densities are relatively low.

The current study provides evidence that pre-logging liana cutting can reduce post-logging liana proliferation but liana cutting did not prevent liana-dominated gaps from developing in the logged forest. In the RIL area $6 \%$ of the gaps were found to have $>60 \%$ liana cover largely resulting from the proliferation of coppices of cut liana stumps. Coppicing rates are likely to be influenced by several factors including the amount of time between liana cutting and logging. In the current study, the amount of successful coppicing may have been kept in check because lianas were cut a full $2 \mathrm{yr}$ prior to logging. Thus, many cut lianas coppiced initially but the sprouts died without ever reaching the canopy presumably for lack of light (J. Gerwing, personal observation). In response to high liana coppicing rates, several studies have employed selective herbicide application to the stumps of cut lianas and found that coppicing was greatly reduced (Appanah and Putz 1984, Fredericksen 2000). Understanding the impacts of cutting lianas and with differing amounts of lead time before logging on post-logging liana regeneration and on need for herbicide use are subjects that merit further study.

The silvicultural benefits of liana cutting carry with them potential costs to the conservation value of the managed forest. Although the results of the current study suggest that the diversity of liana species that regenerated in logging gaps was not negatively affected by liana cutting, because diameter growth in lianas is typically very slow (e.g., a mean annual increment of $1.4 \mathrm{~mm}$ was recorded for 15 species in Panama [Putz 1990]) a diverse assemblage of large diameter climbing lianas will be slow to recover following liana cutting. Indeed, $8 \mathrm{yr}$ following liana cutting and logging there were $14 \%$ fewer species of lianas represented by climbing individuals $>1 \mathrm{~cm}$ diameter in a 0.2 -ha transect in the study forest than there were prior to logging (Gerwing and Vidal 2002). Furthermore, $8 \mathrm{yr}$ postcutting liana basal area at the stand level had regained $<20 \%$ of the precutting value. Such sharp reductions in liana abundance could negatively impact animal species that use them for food and intercrown walkways (Gentry 1991, Peres 1993). In the study forest an attempt was made to cut all climbing lianas prior to logging. Future studies could focus on liana cutting protocols that seek to balance the silvicultural goals of minimizing logging damage and post-logging liana proliferation with the conservation goal of preserving the beneficial roles that lianas are likely to play in the forest ecosystem.

\section{ACKNOWLEDGMENTS}

We would like to thank the World Wildlife Fund for Nature, Brazil (WWF) and the U.S. Agency for International Development (USAID) for financial support; Damião Farias, Miguel Lopes, and Manuel Farias for assistance in the field; and Mark Schulze, Jack Putz, and two anonymous reviewers for helpful comments on the manuscript.

\section{Literature Cited}

Appanah, S., and F. E. Putz. 1984. Climber abundance in virgin dipterocarp forest and the effect of pre-felling climber cutting on logging damage. Malaysian Forester 47:335432.

Baars, R., and D. Kelly. 1996. Survival and growth responses of native and introduced vines in New Zealand to light availability. New Zealand Journal of Botany 34:389-400.

Babweteera, F., A. Plumptre, and J. Obua. 2000. Effect of gap size and age on climber abundance and diversity in Budongo Forest Reserve, Uganda. African Journal of Ecology 38:230-237.

Barreto, P., P. Amaral, E. Vidal, and C. Uhl. 1998. Costs and benefits of forest management for timber production in eastern Amazonia. Forest Ecology and Management 108:9-26.

Beekman, F. 1981. Structural and dynamic aspects of the occurrence and development of lianes in the tropical rain forest. Department of Forestry, Agricultural University, Wageningen, The Netherlands.

Buschbacher, R. J. 1990. Natural forest management in the humid tropics: ecological, social, and economic considerations. Ambio 19:253-258.

Chapman, C. A., L. J. Chapman, L. Kaufman, and A. E. Zane. 
1999. Potential causes of arrested succession in Kibale National Park, Uganda: growth and mortality of seedlings. African Journal of Ecology 37:81-92.

Dalling, J. W., and J. S. Denslow. 1998. Soil seed bank composition along a forest chronosequence in seasonally moist tropical forest, Panama. Journal of Vegetation Science 9: 669-678.

Dawkins, H. C. 1961. New methods of improving stand composition of tropical forests. Caribbean Forester JanuaryJune: $12-20$.

Fisher, J. B., and F. W. Ewers. 1991. Structural responses to stem injury in vines. Pages 99-124 in F. E. Putz and H. A. Mooney, editors. Biology of vines. Cambridge University Press, Cambridge, UK.

Fox, J. E. D. 1968. Logging damage and the influence of climber cutting prior to logging in the lowland dipterocarp forest of Sabah. Malaysian Forester 31:326-347.

Fox, J. E. D. 1976. Constraints on the natural regeneration of tropical moist forest. Forest Ecology and Management 1:37-65.

Fredericksen, T. S. 2000. Selective herbicide applications for control of lianas in tropical forests. Journal of Tropical Forest Science 12:561-570.

Fredericksen, T. S., and B. Mostacedo. 2000. Regeneration of timber species following selection logging in a Bolivian tropical dry forest. Forest Ecology and Management 131: 47-55.

Gentry, A. H. 1991. Breeding and dispersal systems of lianas. Pages 393-423 in F. E. Putz and H. A. Mooney, editors. The biology of vines. Cambridge University Press, Cambridge, UK.

Gerwing, J. J., and D. L. Farias. 2000. Integrating liana abundance and forest stature into an estimate of aboveground biomass for an eastern Amazonian forest. Journal of Tropical Ecology 16:327-336.

Gerwing, J. J., and E. Vidal. 2002. Changes in liana abundance and species diversity eight years after liana cutting and logging in an eastern Amazonian forest. Conservation Biology 16:544-548.

Hegarty, E. E. 1989. The climbers, lianes and vines. Pages 339-353 in H. Lieth and M. J. A. Werger, editors. Tropica rain forest ecosystems. Elsevier, New York, New York, USA.

Hegarty, E. E., and G. Caballé. 1991. Distribution and abundance of vines in forest communities. Pages 313-336 in F E. Putz and H. A. Mooney, editors. Biology of vines. Cambridge University Press, Cambridge, UK.

Holm, S. 1979. A simple sequentially rejective multiple test procedure. Scandinavian Journal of Statistics 6:65-70.

Johns, J. S., P. Barreto, and C. Uhl. 1996. Logging damage during planned and unplanned logging operations in the eastern Amazon. Forest Ecology and Management 89:5977.
Kennedy, D. N., and M. D. Swaine. 1992. Germination and growth of colonizing species in artificial gaps of different sizes in Dipterocarp rain forest. Philosophical Transactions of the Royal Society of London series B 335:357-366.

Klinge, H., and W. A. Rodrugues. 1973. Biomass estimation in a central Amazonian rain forest. Acta Cientifica Venezolana 24:225-237.

Laurence, W. F., D. Pérez-Salicrup, P. Delamônica, P. Fearnside, S. D'Angelo, A. Jerozolinski, L. Pohl, and T. Lovejoy. 2001. Rain forest fragmentation and the structure of Amazonian liana communities. Ecology 82:105-116.

Magurran, A. E. 1988. Ecological diversity and its measurement. Princeton University Press, Princeton, New Jersey, USA.

Minitab. 1996. Minitab release 11.21. Minitab, State College, Pennsylvania, USA.

Neil, P. E. 1984. Climber problem in Solomon Islands forestry. Commonwealth Forestry Review 63:27-34.

Parren, M., and F. Bongers. 2001. Does climber cutting reduce felling damage in southern Cameroon? Forest Ecology and Management 141:175-188.

Peres, C. A. 1993. Diet and feeding ecology of saddle-back (Saguinus fuscicollis) and moustached (S. mystax) tamarins in an Amazonian terra firme forest. Journal of Zoology 230:567-592.

Putz, F. E. 1983. Liana biomass and leaf area of a "Tierra Firme" forest in the Rio Negro basin, Venezuela. Biotropica 15:185-189.

Putz, F. E. 1984a. The natural history of lianas on Barro Colorado Island, Panama. Ecology 65:1713-1724.

Putz, F. E. 1984b. How trees avoid and shed lianas. Biotropica 16:19-23.

Putz, F. E. 1990. Liana stem diameter growth and mortality rates on Barro Colorado Island, Panama. Biotropica 22: 103-105.

Rice, W. R. 1989. Analyzing tables of statistical tests. Evolution 43:223-225.

Schnitzer, S. A., and W. P. Carson. 2001. Treefall gaps and the maintenance of species diversity in a tropical forest. Ecology 82:913-919.

Schnitzer, S. A., J. W. Dalling, and W. P. Carson. 2000. The impacts of lianas on tree regeneration in tropical forest canopy gaps: evidence for an alternative pathway of gapphase regeneration. Journal of Ecology 88:655-666.

Uhl, C., R. Buschbacher, and E. A. S. Serrão. 1988a. Abandoned pastures in eastern Amazonia. I. Patterns of plant succession. Journal of Ecology 76:663-681.

Uhl, C., K. Clark, N. Dezzeo, and P. Maquirino. 1988b. Vegetation dynamics in Amazonian treefall gaps. Ecology 69: 751-763.

Vidal, E., J. Johns, J. J. Gerwing, P. Barreto, and C. Uhl. 1997. Vine management for reduced-impact logging in eastern Amazonia. Forest Ecology and Management 98: 105-114. 